\title{
Level of maternal education and performance of Black, South African infants on the 1996 Griffiths Mental Development Scales
}

\section{K Cockcroft, Z Amod, B Soellaart}

School of Human and Community Development, Discipline of Psychology, University of the Witwatersrand, Johannesburg, South Africa

\begin{abstract}
Objective: The study compared the performance on the Griffiths Mental Development Scales of Black, South African infants with mothers who had twelve or more years of education and who were professionally employed with infants of mothers with fewer than twelve years of education and who were employed in non-professional jobs. Method: The sample consisted of 40 infants (aged 13-16 months), to whom the Griffiths Mental Development Scales was administered. Results: The infants with professional mothers performed significantly better than their counterparts with non-professional mothers on the General Quotient, as well as on the Locomotor Scale. While maternal level of education did not appear to distinguish between infants in terms of social, fine motor, language, hearing, processing speed or practical reasoning, it did discriminate in terms of gross-motor functioning. Conclusion: It is suggested that, as the infant develops, the skills assessed by the Griffiths Scales, which are initially differentiated, become increasingly interrelated. Consequently, poor gross-motor skills, which may be more likely in infants from a low socio-economic status, may have far-reaching implications. Thus, it is important to consider maternal level of education and the socio-economic status background of the infant, as this may influence overall performance on the Scales.
\end{abstract}

Keywords: Developmental assessment, Maternal level of education, Griffiths Mental Development Scales

Received: 05-02-2007

Accepted: 01-06-2007

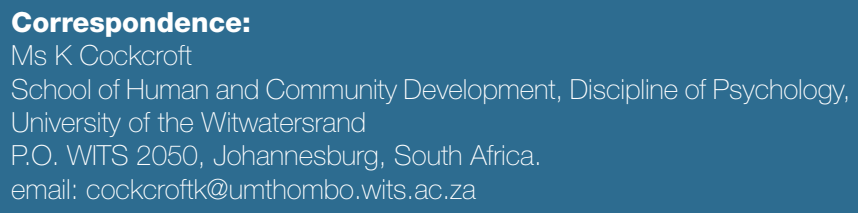

\section{Introduction}

Maternal level of education and profession have not been well researched as mediating factors in infant development. The impact of maternal employment on child development remains a topic of much informal debate. Mothers who have a tertiary education are likely to enter professional occupations, and subsequently to belong to a middle to high socio-

economic group. This in turn influences access to financial
\end{abstract}

resources, diet, health care and sanitary facilities, quality of education, exposure to books and technology, and familiarity with Western cultural mores, which are all likely to have an effect on child development and psychological functioning. ${ }^{1,2,3}$ However, it has been demonstrated that maternal employment during the first three years of a child's life has a deleterious (albeit small) effect on the child's intellectual development. ${ }^{4}$ The general increase in the employment of women over the past few years, together with the increase in single parent households, is suggested to afford parents less time and energy to invest in their children. Consequently, this paper reports on the results of a comparison between the performance of infants with educated, professionally employed mothers versus those with less educated, nonprofessional mothers, on the Griffiths Mental Development 
Scales (hereafter referred to as the Griffiths Scales) ${ }^{5}$, one of the most popular measures of child and infant development.

There is considerable evidence that developmental assessment measures can be used effectively for the early identification and prevention of learning and development difficulties in early childhood. As a result, increasing interest has been shown in early assessment and intervention in order for children to realise their full potential. However, in order to achieve these goals effectively, the assessment measures used need to be applicable within culturally diverse contexts, particularly within South Africa, with its broad range of cultural and socio-economic groupings, ${ }^{6,1}$ Testing and assessment have been heavily criticized as possessing limited value for culturally diverse populations.8,9,10 Despite these criticisms, it has also been pointed out that, regardless of its flaws, testing remains more reliable and valid than any of the limited number of alternatives. It is argued that since testing plays a crucial role within assessment internationally, the focus should be on valid and reliable tests for use within multi-cultural and multi-lingual societies. ${ }^{11}$

Nonetheless, the development of culturally relevant tests is likely to be a long and costly endeavour, possibly even "an unattainable goal" 12 , because South Africa has many different cultural groups at different stages of westernisation, with differing linguistic and educational abilities. For this reason, it is cautioned that test users do not discard international tests too impulsively. Rather, it seems feasible to use existing, wellresearched tests, with culturally loaded items identified and replaced, and local norms ultimately developed. ${ }^{12}$

While the current rejection of existing western tests within South Africa stems from a genuine concern for cultural differences between groups, Shuttleworth-Jordan ${ }^{12}$ points out the problems with an indiscriminate rejection of all such tests Firstly, such an attitude fails to acknowledge brain-behaviour relationships and cognitive processes that are common to all humans. Secondly, research resources may be profitably spent on the modification of existing tests for use with urbanised and educated South African populations. This would be preferable to "embarking on the path of separatist test development which has limited international relevance, and which may well amount to activity which is no more fruitful than the reinvention of the wheel". ${ }^{12}$ A general disregard of all western tests does not take into account the different levels of urbanisation, westernisation and education that exist in Africa. Even within particular cultural groups, differences exist. Most obvious are the persistent score differences by socio-economic status on a range of psychometric measures. ${ }^{13}$ It is inevitable that when individuals are grouped in ways related to differential educational opportunities, their scores on psychometric measures will differ.

A major factor that has been found to affect test performance in South Africa, is education, both that of the testee and his/her parents. ${ }^{14,15}$ This means that the use of available, internationally relevant tests would be a viable option, but only for educated and westernised individuals. Less literate, less westernised and less educated groups require the development of new and culturally appropriate measures. ${ }^{2}$ Subsequently, it is impossible to ignore the sociopolitical and historical context in which the child has developed.
In South Africa, the impact of apartheid continues to influence testing and assessment. In the past, psychological tests were developed along racial lines as there was "little specific need for common tests because the various groups did not compete with each other". ${ }^{3}$ While many tests were developed or adapted for the White population, considerably fewer tests were developed for Black South Africans. As a result, it has become common practice to use tests developed for White, westernised populations with other population groups and to "apply the norms with caution". ${ }^{16}$ The price of such practice may be inaccurate levels of over-identification or under-identification of children at risk for developmental difficulties. ${ }^{17}$ Of specific concern to the assessment of Black South African children is the over-identification of at risk children. The cost of over-identification can be high, for example, being labelled as mentally handicapped as a result of barriers to learning and development.

Assessment practitioners in South Africa are now required to demonstrate the validity, fairness and unbiased nature of any assessment measures which they use. ${ }^{16}$ This presents a challenge to those working within the field, particularly since the majority of tests are developed outside South Africa. Consequently, the current paper reports on part of a larger study that examined the validity of the Griffiths Scales for Black, South African infants. It presents a comparison between the performance of a sample of Black South African infants with highly educated, professional mothers and a similar group with less educated, non-professional mothers on the Griffiths Scales. ${ }^{5}$

The Griffiths Scales are one of the most widely used and researched measures to assess both general and specific aspects of childhood development. ${ }^{18}$ Numerous international studies have reported positively on their psychometric properties. 19,20,21 The Scales have also been utilized with many different populations within South Africa, but most of these have focused on the scales for children aged 2 to 8 years. ${ }^{18,22-}$ ${ }^{33}$ and very few studies have been conducted with infants. ${ }^{34,35}$ In addition, there is limited research about the influence of maternal level of education, profession or socio-economic status on performance on the Griffiths Scales. One of the few such studies investigated the influence of gender, language and socio-economic status on the Griffiths Scales scores of a sample of 60 normal English- and Afrikaans-speaking, White South African children, with a mean age of 5 years. ${ }^{22}$ It was found that children from high and low socio-economic groups differed significantly on the General Quotient (GQ), as well as on their performance on four of the six Scales (namely, Hearing and Speech, Eye Hand co-ordination, Practical Reasoning and Performance). The researcher speculated that the differences were due to variations in the quality of childcare and the opportunities afforded to children from higher socio-economic groups for stimulation. ${ }^{22}$ Other studies have also found that there were significant differences in the performance of South African Indian children from differing socio-economic groups on the Griffiths Scales, with children from higher groups performing significantly better. ${ }^{24,21,35}$ Although none of these studies examined the infant scales of the Griffiths Scales, a study on this population ${ }^{39}$ found that there were social class differences in the developmental performance of British infants under the age of 2 years on the 1980 version of the Griffiths Scales. 
It was within the context outlined above that the current study emerged. Since the development of a new culturally fair infant developmental assessment instrument is not a possibility in the near future, it is imperative to utilise the available resources for the early identification of developmental difficulties. The Griffiths Scales are widely regarded as a culture fair test $29,37,38$, which is sufficient reason to pursue further research regarding their applicability for different groups. This paper reports on a comparison between the performance of Black, South African infants with highly educated, professionally employed mothers and those with less educated, non-professional mothers, on the Griffiths Scales.

\section{Method}

\section{Sample}

The sample consisted of 40 South African, Black infants - 13 to 16 month old- (21 boys and 19 girls) residing in

Johannesburg, Gauteng. The distinction between infants with highly educated, professional mothers and those with less educated, non-professional mothers was based on level of education and occupation of the infant's mother, as determined from the responses on the Biographical Questionnaire. The motivation for using maternal education and occupation was that they have been identified as two of the main indicators of socio-economic status, with which they are inextricably linked. ${ }^{39}$ Table I shows the distribution of level of education of the mothers of the sample.

\section{Table I: Maternal levels of education}

\begin{tabular}{|l|l|l|}
\hline LEVEL OF EDUCATION & N & $\%$ \\
\hline Completed Primary School (Grades 1 -7) & 1 & $2.5 \%$ \\
Completed Grade 10 & 8 & $20 \%$ \\
Completed Grade 12 (Matric) & 11 & $27.5 \%$ \\
Completed Tertiary or Post-Matric Studies & 20 & $50 \%$ \\
\hline
\end{tabular}

Fifty percent of the mothers had received some tertiary education and were employed in professional occupations. Of the remainder, $27.5 \%$ had received twelve years of formal education, $20 \%$ had completed ten years of formal education and $2.5 \%$ of the mothers had seven years or less of formal education. None of the latter three groups of mothers were employed in professional occupations.

\section{Instruments}

The Griffiths Scales were developed in the United Kingdom in 1954 by Ruth Griffiths, who observed children in their natural environments, while engaged in everyday activities. ${ }^{37}$ Griffiths' purpose was to develop an instrument containing a comparative profile of abilities across various domains of development, which would facilitate early diagnosis of deficits in child development.

The Griffiths Scales for infants from birth to 1 year 11 months consist of five scales (Scales A-E). The Locomotor Scale (Scale A) measures developing gross-motor skills important for an upright posture, walking, running, and climbing. It allows for the observation of physical weakness or disability or defects of movement. The Personal-Social Scale (Scale B) requires more input from the primary caregiver than the other scales as it measures early adaptive and self-help behaviour typically seen at home, as well as social behaviour that develops through early adult-child interactions. The Hearing and Speech Scale (Scale C) is considered to be the most intellectual Scale and evaluates the development of language by measuring responses to environmental sounds and speech, as well as the production of sounds and words. The Eye and Hand Co-ordination Scale (Scale D) consists of items requiring fine-motor handwork and visual ability. It assesses manipulative skills such as visual tracking, reaching and grasping, pen and paper skills and object manipulation. The Performance Scale (Scale E) evaluates manipulation skill, speed and precision of work. It assesses the application of developing skills in novel situations and examines simple object exploratory behaviour, object permanence and manipulation of form-board items.

The Griffiths Scales are criterion-referenced in nature, and so the child is compared to an established criterion and not to another child. This is important for cross-cultural assessment, as it assesses the degree of mastery of the individual and serves to describe rather than to compare performance. ${ }^{40} \mathrm{~A}$ mental age can be calculated for each of the five Griffiths scales and a General Quotient (GQ) may be obtained from the combined scale scores.

\section{Developmental Questionnaire}

Foxcroft's ${ }^{41}$ neurological questionnaire, based on Petersen and Eeg-Olofsson's ${ }^{42} 13$ criteria for evaluating central nervous system development in children, was adapted and used to determine normal neurological development in the sample of infants. This questionnaire claims to be one of the most effective and comprehensive, indirect measures of determining the normality of brain functioning in children. ${ }^{41}$

\section{Biographical Questionnaire}

Prior to the assessment of the infants, the infant's mothers were requested to fill in a Biographical Questionnaire. The purpose of this questionnaire was to obtain relevant information regarding the age, gender and nationality of the infant, as well as the infant's birth history and the mother's occupation and level of education.

The Biographical Questionnaire was adapted from Bhamjee's ${ }^{24}$ Parent Questionnaire for this study. Since Bhamjee's study included older children, she included items which were not relevant for the infants in the present study (e.g. school performance).

\section{Procedure}

Once permission had been obtained from the relevant officials at two Johannesburg health clinics and from the principals and teachers at two daycare centres, letters were sent to parents/caregivers of infants who fell within the relevant age category, informing them of the study. Those who consented to their child's participation were given the developmental and biographical questionnaires to complete. A translator was used to interpret information for mothers who were not fluent in English. In many instances, the parent gave the necessary instructions to the child and also responded to questions about the infant's general development, in 
accordance with the Griffiths Scales administration procedures.

Testing was conducted by an appropriately trained and registered tester on the premises of the clinics and daycare centres. The Griffiths Scales were administered and scored according to standardised procedure ${ }^{5}$ and mothers received individual feedback on their child's assessment results.

\section{Results}

Several extraneous variables which could influence the results, namely age, developmental normality, and urban or rural residence, were controlled for by holding them constant. The variables gender and socio-economic status were controlled for by including them in the research design.

On the basis of the Developmental Questionnaire, it was ascertained that the majority of the sample (93\%) experienced no complications at birth, had not suffered any significant medical conditions such as meningitis (75\%), encephalitis (95\%), convulsions (98\%), concussion (100\%), anaemia (93\%), head injury (100\%), allergy (88\%) or extreme temperature (88\%). No children were on any medication at the time of the assessment and there was no history of epilepsy in any of the families whose infants formed the sample.
Tables II and III represent the descriptive statistics obtained on the five separate scales, as well as on the General Quotient (GQ) of the Griffiths Scales, for infants with highly educated, professional and less educated, non-professional mothers respectively.

As depicted in Table II, the mean GQ for the infants with professional mothers $(\mathrm{n}=20)$ was 104.6, indicating Average (ie. 90-110) general performance. The range between the minimum and maximum scores on the various scales of the Griffiths Scales is generally fairly small, with standard deviations of between 5.52 and 12.00, which indicates little variation within the sample, most probably due to it being a restricted one.

Table III illustrates a mean GQ of 99.75 for infants with non-professional mothers $(n=20)$, also indicating Average general performance for this group. The range between the minimum and maximum scores obtained on the various Scales was slightly wider than for the group with professional mothers, and the standard deviations varied from 7.94 to 13.42, suggesting somewhat greater variation within the group with non-professional mothers.

Table IV presents the results of the independent pairs ttest between the means obtained by infants with professional and non-professional mothers, for each scale and for the total

Table II: Mean Quotients and Standard Deviations (SD) on the Griffiths Scales for infants with Professional Mothers ( $n=20$ )

\begin{tabular}{|l|l|l|l|l|l|l|l|}
\hline Griffiths Scale & Mean Quotient & Performance Classification & Median & Min score & Max score & Range & SD \\
\hline General Quotient (GQ) & 104.6 & AVERAGE & 104.5 & 94 & 112 & 18 & 5.52 \\
Scale A (Locomotor) & 103.05 & AVERAGE & 104 & 82 & 112 & 30 & 9.45 \\
Scale B (Personal-Social) & 97.55 & AVERAGE & 100 & 82 & 113 & 31 & 8.92 \\
Scale C (Hearing \& Speech) & 100.4 & AVERAGE & 100 & 89 & 108 & 19 & 5.55 \\
Scale D (Eye-Hand) & 114.65 & ABOVE AVERAGE & 116 & 102 & 126 & 24 & 7.26 \\
Scale E (Performance) & 108.15 & AVERAGE & 107 & 91 & 140 & 49 & 12.00 \\
\hline
\end{tabular}

Table III: Mean Quotients and Standard Deviations (SD) on the Griffiths Scales for infants with Non-Professional Mothers (n= 20)

\begin{tabular}{|l|l|l|l|l|l|l|l|}
\hline Griffiths Scale & Mean Quotient & Performance Classification & Median & Min score & Max score & Range & SD \\
\hline General Quotient (GQ) & 99.75 & AVERAGE & 100 & 82 & 112 & 30 & 8.69 \\
Scale A (Locomotor) & 92.05 & AVERAGE & 97.5 & 64 & 108 & 44 & 13.42 \\
Scale B (Personal-Social) & 91.6 & AVERAGE & 91 & 69 & 113 & 44 & 10.19 \\
Scale C (Hearing \& Speech) & 100.25 & AVERAGE & 101.5 & 86 & 114 & 28 & 7.94 \\
Scale D (Eye-Hand) & 113.9 & ABOVE AVERAGE & 112 & 96 & 134 & 38 \\
Scale E (Performance) & 103.6 & AVERAGE & 106.5 & 88 & 123 & 35 & 9.58 \\
\hline
\end{tabular}

Table IV: Comparisons between infants with professional mothers and infants with non-professional mothers on the Griffiths Scales

\begin{tabular}{|l|c|c|c|}
\hline Griffiths Scale & $\begin{array}{c}\text { Professional Mean } \\
(n=20)\end{array}$ & $\begin{array}{c}\text { Non-Professional Mean } \\
(n=20)\end{array}$ & $t$-test \\
\hline General Quotient (GQ) & 104.6 & 99.75 & $2.107^{*}$ \\
Scale A (Locomotor) & 103.05 & 92.05 & $2.119^{*}$ \\
Scale B (Personal-Social) & 97.55 & 91.6 & 1.38 \\
Scale C (Hearing \& Speech) & 100.4 & 100.25 & 0.049 \\
Scale D (Eye-Hand) & 114.65 & 113.9 & 0.18 \\
Scale E (Performance) & 108.15 & 103.6 & 0.937 \\
\hline${ }^{*} p<0.05$ & & & \\
\hline
\end{tabular}


scale of the Griffiths Scales. The data in Table IV indicates that the infants with professional mothers performed significantly better than their counterparts with non-professional mothers on the General Quotient (GQ) as well as on Scale A (Locomotor). The differences evident in the GQ are likely to reflect the difference on the Locomotor Scale, with which it is correlated. The two groups of infants did not differ significantly on the other four scales.

\section{Discussion}

Of the 135 million infants born throughout the world, more than $90 \%$ live in low-income or developing countries. ${ }^{43}$ Despite this, only a small percentage of published research addresses children who come from such backgrounds. ${ }^{44}$ Tomlinson ${ }^{44}$ cautions that the typical infant lives in an environment that is very different from that inhabited by the typical child development researcher. It is important therefore, that the different circumstances of infants be considered, particularly in the case of developmental assessment, since social factors, notably maternal education level, are among the strongest predictors of poor neurodevelopmental outcome in infants. ${ }^{45}$

In the current study, the infants with highly educated, professional mothers performed significantly better than infants with less highly educated, non-professional mothers on the GQ and the Locomotor Scale (Scale A). Although Allan's ${ }^{22}$ sample was a group of 5-year old children, he also found significant differences between English and Afrikaans high and low socio-economic groups on the GQ and on four of the six Scales (namely, Hearing and Speech, Eye Hand coordination, Practical Reasoning and Performance). The discrepancy in the ages of the samples concerned may partly account for the variation in Scales of the Griffiths Scales in which differences were found. The effects of maternal level of education and by association, socioeconomic status, may become more marked as the child develops, accounting for the more pervasive differences found by Allan. ${ }^{22}$

The results of the current study indicate just a single area of difference in the performance of infants with highly educated and less educated mothers, that is, in terms of locomotor ability (differences in the GQ were likely to be reflective of the difference within the Locomotor Scale). While home environment appears to play an important role in the cognitive and academic outcome of high risk infants, findings are inconsistent with regard to its influence on motor skills. ${ }^{46}$ However, Goyen and Lui ${ }^{13}$ found that the development of gross motor skills appears to be differentially influenced by the home environment, with infants from lower socio-economic groups performing significantly poorer than their wealthier counterparts. This may subsequently impact on the general intellectual functioning of these infants as motor development during these formative years provides a foundation for subsequent development and optimises occupational performance in the areas of self-care, learning, recreation and play.

Further evidence for the close connection between gross motor functioning and intellectual and social development is revealed by the findings of Luiz et al. ${ }^{18}$ Within their sample of 180, 4 to 7 year old South African children, the more discrete cognitive, motor and personal-social functions tapped by the Griffiths Scales were not clearly delineated when subjected to a factor analysis. With the exception of Scale E (Performance), all of the Scales seemed to tap complex skills or more than one construct, and aspects of the constructs tapped appeared to differ for the various age groups in the study (ie. 4 to 5 year olds, 5 to 6 year olds and 6 to 7 year olds). These findings would support the tentative proposal that the differences found between the infants in the current study may become more pronounced and/or widespread with age. Luiz et al. ${ }^{18}$ concluded that their findings illustrated the necessity for further investigation into the construct validity of the Griffiths Scales. While Luiz et al.18 did not include infants in their study, their findings suggest that locomotor skill in young children is closely associated with a range of intellectual and social skills and so poor gross motor functioning could have far reaching implications.

\section{Conclusion}

The results of this study should be interpreted with caution for several reasons. First, it represented an exploratory, pilot study and so further confirmatory studies would be necessary, due to the small sample size. Second, the sample was limited to infants from urban areas only. Although Hanson et al. ${ }^{36,47}$ did not find any significant differences in the GQ of the Griffiths Scales for infants under the age of 2 years, from urban and rural regions, these were not South African children, where the urban-rural divide may be more marked. Since there is also some evidence to indicate that urban children perform better than rural children on certain cognitive skills ${ }^{48}$, the performance of a larger, more representative sample of high and low income infants on the Griffiths Scales should be undertaken. Third, caution should be exercised in regarding the different mean scores obtained by the infants from different socio-economic groups in the current study as necessarily an index of bias. It would be easy to draw such a conclusion, since bias is theoretically any difference or dividing factor between those groups of people taking the test, and so could exist in terms of the test's content, norms or the testing situation. ${ }^{3}$ However, it would be necessary to conduct an examination of item bias or score comparability with a larger sample in order to determine whether members of various socio-economic groups demonstrate specific patterns of responses.

Despite these limitations, the current study provides a description of the performance of Black infants with highly educated, professional and less well educated, nonprofessional mothers on the Griffiths Scales. Maternal level of education and occupation are generally correlated with income ${ }^{39}$, which reflects the potential for social and economic resources that are available to the infant.

The findings of the current study suggest that the contextual factor of socio-economic status be considered in the interpretation of Griffiths Scales performance, as it could prove to be an important aspect that impacts on the infant's general functioning on this measure. There are also some practical implications that emerge from these findings. The main one is that it may be necessary for practitioners to propose ways in which gross motor skills in infants can be improved, thereby promoting intellectual and social development (Appendix 1). This is even more critical when the infant has a less educated mother and belongs to a lower socio-economic group. 


\section{References}

1. Brislin RW. Applied Cross-Cultural Psychology. New York: Sage Publications, Inc, 1990.

2. Nell V. Science and politics meet at last, the insurance industry and neuropsychological norms. S Afr J Psychol 1997; 27: 43-49.

3. Owen K. Test bias, the validity of the Junior Aptitude Tests for various population groups in South Africa regarding constructs measured. S Afr J Psychol 1991; 21 (2): 113-118.

4. Ruhm J. Parental employment and child development. J Hum Resour 2004; XXXIX (1): 155-192.

5. Huntley M. The Griffiths Mental Development Scales: From birth to 2 years. ARICD, 1996

6. Fitzgerald HE. Infant mental health: An interdisciplinary and international perspective for families with infants and toddlers. S Afr J Child Adol Ment Hlth 1997; 9 (2): 168-172.

7. Nell V. Standardising the WAIS-III and the WMS-III for South Africa, Legislative, psychometric and policy issues. S Afr J Psychol 1999; 29(3): 128-137.

8. Foxcroft CD. Psychological Testing in South Africa: Perspectives Regarding Ethical and Fair Practices. Eur J Psychol Assess 1997; 13 (3): 229-235.

9. Nzimande B. To test or not to test. Paper presented at the Congress of psychometrics for Psychologists and Personnel Practitioners, Pretoria 1995.

10. Sehlapelo M, Terrreblanche M. Psychometric testing in South Africa: Views from above and below. Psychology in Society 1996; 21:4959.

11. Plug C. In: Foxcroft CD. Psychological Testing in South Africa: Perspectives Regarding Ethical and Fair Practices. Eur J Psychol Assess 1997;13 (3): 229-235.

12. Shuttleworth-Jordan AB. On not reinventing the wheel, A clinical perspective on culturally relevant test usage. S Afr J Psychol 1996; 26: 92-102.

13. Goyen T, Lui K. Longitudinal motor development of "apparently normal" high-risk infants at 18 months, 3 and 5 years. Early Hum Dev 2002; 103-115.

14. Kriegler SM, Skuy M. (1996). Perspectives on psychological assessment in South African schools. In: Engelbrecht P, Kriegler SM \& Booysen MI, eds, Perspectives on Learning difficulties: International Concerns and South African Realities. Pretoria: Van Schaik, 1996: 109-122.

15. Skuy MS, Schutte E, Fridjhon P, O'Carroll S. Suitability of published neuropsychological test norms for urban, African secondary school students in South Africa. Pers Indiv Differ 2001; 30: 1413-1425.

16. Foxcroft CD, Roodt G. An introduction to psychological assessment in the South African context (2nd Ed.). Cape Town, Oxford University Press, 2005:13-235.

17. Brooks-Gunn J. Identifying the vulnerable young children. In: Rogers $D E$. Ginsberg E,eds, Improving the life chances of children at risk. Plenum Press, New York , 1990: 19-58.

18. Luiz, DM, Foxcroft, CD \& Povey, J. The Griffiths Mental Development Scales: A factorial validity study. S Afr J Psychol 2006; 36 (1): $192-$ 214.

19. Griffiths R. The abilities of young children. Amersham, A.R.I.C.D, 1984.

20. Hanson R. Item reliability for the Griffiths Mental Development Scales. Child Care Hlth Dev 1982; 8: 151-161.

22. Heimes L. The comparison of the JSAIS and the Griffiths Developmental Scale scores of 3-5 year old boys and girls. Unpublished Master's thesis, University of Port Elizabeth, South Africa, 1983
23. Allan MM. A comparison of the performance of normal preschool South African and British children on the Griffiths Mental Development Scales. Unpublished Master's thesis, University of Port Elizabeth, 1988.

24. Allan MM. The performance of normal preschool South African children on the Griffith Scales of Mental Development: A Comparative Study. Unpublished Doctoral thesis, University of Port Elizabeth, 1992

25. Bhamjee RA. A comparison of the performance of normal British and South African children on the Griffiths Mental Development Scales. Unpublished Doctoral thesis, University of Port Elizabeth, 1991.

26. Lombard M. The SETT and the Griffiths Mental Development Scales, A correlative study. Unpublished Master's thesis, University of Port Elizabeth, 1989.

27. Luiz DM. A child with a hearing loss, A longitudinal study. In: Luiz DM, ed, Griffith Scales of Mental Development, South African studies (Research Papers No. C25). Port Elizabeth, University of Port Elizabeth 1988a: 44-51.

28. Luiz DM. A battered child: A follow up study. In D.M. Luiz (Ed.), Griffith Scales of Mental Development, South African studies (Research Papers No. C25). Port Elizabeth, University of Port Elizabeth 1988b: 52-58.

29. Luiz DM. A comparative study of two scales of language development, The Reynell and the Griffiths. In: Luiz DM, ed, Griffith Scales of Mental Development, South African studies (Research Papers No. C25). Port Elizabeth, University of Port Elizabeth, 1988c: 16-20.

30. Luiz DM. Children of South Africa: In search of a developmental profile. Inaugural and Emeritus Address. Port Elizabeth, University of Port Elizabeth 1994.

31. Luiz DM, Foxcroft $C D$, Stewart $R$. The construct validity of the Griffiths Mental Development Scales. Child Care Hlth Dev 2001; 27: 73-83.

32. Mothule VB. The Aptitude Test for Beginners and the Griffiths Mental Development Scales, An investigation into the assessment of the cognitive abilities of grade 1 children. Unpublished Master's thesis, Medical University of South Africa, Pretoria 1990.

33. Tukulu AN. The Denver II Scale and the Griffiths Mental Development Scales: A Correlational study. Unpublished master's thesis, University of Port Elizabeth 1996.

34. Kotras H. Exploring the developmental profiles of black South African HIV+ infants using the revised Griffiths Mental Development Scales. Unpublished Master's thesis, University of Port Elizabeth 2001.

35. Sweeney K. Cluster analysis of the Griffiths profiles of a white South African Clinical population. Unpublished Master's thesis, University of Port Elizabeth 1994.

36. Hindley CB. The Griffiths Mental Development Scales: Scores and predictions from 3 to 18 months. J of Child Psychol Psyc 1960; 1: 99112.

37. Hanson R, Aldridge Smith J, Hume W. Achievements of infants on items of the Griffiths scales: 1980 compared with 1950. Child Care Hith Dev 1985; 11: 91-104.

38. Griffiths R.The abilities of young children. London, Child Development Research Centre 1970.

39. Victora MD, Victora CG, Barros FC. "Cross-cultural" differences in development rates, a comparison between British and Brazilian children. Child Care Hlth Dev 1990; 16: 151-164.

40. Sirin SR. Socioeconomic status and academic achievement: A metaanalytic review of research. Rev Educ Res 2005; 75(3): 417-453. 
41. Sattler JM. Assessment of children's intelligence and special abilities, 2nd Edition. Boston: Allyn and Bacon, 1982.

42. Foxcroft CD. The use of the Reitan-Indians Neuropsychological Test Battery in South Africa: A cross-ethnic comparison of normal preschool children. Unpublished doctoral dissertation, University of Port Elizabeth 1985.

43. Petersen I, Eeg-Olofsson O. The development of the electroencephalogram in normal children from the age of 1 through 15 years. Neuropadiatrie 1970; 2: 247-304.

44. Population Reference Bureau. Untitled fact sheet. [cited 7 July 2006] Available

from:http://www.prb.org/content/navigationMenu/Other_reports/20 00-2005/ sheet1.html

45. Tomlinson M. Culture and infancy: a critical examination. S Afr J Child Adol Mnt Hlth 2003; 15(1): 45-48.

46. Sommerfelt K, Ellertsen B, Markestad T. Parental factors in cognitive outcome of non-handicapped low birthweight infants. Arch Dis Child 1995; 73: 135-142.

47. Dammann O, Walther H, Allers B, Schroder M, Drescher J, Llutz D. Development of a regional cohort of very low birthweight children at 6 years: Cognitive abilities are associated with neurological disability and social background. Dev Med Child Neurol 1996; 38; 97-108.

48. Hanson R, Aldridge Smith J, Hume, W. Achievements of infants on items of the Griffiths scales: 1980 compared with 1960. Child Care Hlth Dev 1987; 13:181-195.

49. Kendal, IM, Verster MA, Von Mollenendorf JW. Test performance of South African blacks. In: Irvine SH. Berry JW, eds, Human Abilities in cultural context. New York: Cambridge University Press, 1988: 299339.

\section{Appendix 1}

Some suggestions for fostering the gross motor skills of infants within a low socio-economic environment, with limited resources, are given below:

- Crawling (develops co-ordination and laterality), for example treasure hunt - crawl to find hidden objects; crawl through an obstacle course; follow the leader.

- Climbing (strengthens muscles, develops posture and provides an opportunity for viewing the environment from different perspectives), for example climb up and down steps; climb over obstacles.

- Balancing (develops control and co-ordination), for example walk along a piece of string or chalk line; climb steps/ladders; use a balance beam/plank.

- Hopping, skipping and running (helps gain body control and balance), for example hopping/skipping/running around obstacles; on the spot; on the toes.

- Jumping (develops overall gross motor skills and co-ordination), for example jumping over objects; jump up to touch suspended objects; jump on tyres, mattresses; jump from one point to another.

- Kicking, for example balls/balloons of different sizes.

- Pushing/pulling (develops control over objects and muscle strength), for example tug of war; pushing objects around an obstacle course.

- Rolling, turning, twisting and bending (develop co-ordination and an awareness of the relationship between upper and lower body and pivot points of neck and feet), for example rolling balls using hands or feet; rolling body from side to side; rolling forwards; stand inside a hoop and turn, twist or bend to reach objects outside the hoop.

\title{
Adjust Your Brain: A Practical Theory for Maximizing Mental Health
}

Paul J. Fitzgerald, Ph.D.

O-books; US\$24.95; Paper; 215pp; 5 11/2" x 8 112";

ISBN 978-1-84694-055-2; October 2007

$\mathrm{O}$ is a symbol of the world, of oneness and unity. O Books explores the many paths of wholeness and spiritual understanding which different traditions have developed down the ages. It aims to bring this knowledge in accessible form, to a general readership, providing practical spirituality to today's seekers.

\section{www.o-books.net}

\author{
Editorial office: O Books, The Bothy, Deershot Lodge, Park Lane, Ropley, \\ Hampshire, SO24 OBE, UK
}

